\title{
The small world of German CEOs: a multi-method analysis of the affiliation network structure
}

\author{
Elena Semenova ${ }^{1} \mathbb{C}$
}

Accepted: 21 January 2021 / Published online: 17 February 2021

(c) The Author(s) 2021

\begin{abstract}
This paper seeks to understand the structure of corporate networks in the period following the dissolution of Deutschland AG ("Germany Inc."). For this purpose, affiliation networks among chief executive officers (CEOs) that are based on common membership in various societal organizations will be examined. I apply an innovative mix of methods for studying a sample of CEOs from the 100 top companies in Germany in the 2010s. Based on social network analysis, I show that the overall affiliation network has all features of a small-world network, i.e., a high clustering coefficient and a short path length among the CEOs. The average degree of separation among German CEOs is only two steps. Another innovative contribution of this paper is its study of the linkage between affiliation network features and patterns of corporate recruitment. Using multiple correspondence analysis, I show that different subgroups of the overall affiliation network have their specific network characteristics and recruitment patterns. Within the network, managers from automotive and technical engineering often assume brokerage positions, while managers from the trade branch are largely isolated. This study shows that the affiliation networks and corporate recruitment patterns are interlinked; the transformation of corporate networks is a dynamic outcome of interrelations among different subgroups within the network, each with distinct educational, professional, and network characteristics.
\end{abstract}

Keywords Corporate governance · Affiliation network · Small world network · Chief executive officers (CEOs) - Social network analysis · Germany · Multiple correspondence analysis

Who is the part of national corporate elites and how these elite members are connected are the foremost questions both researchers on corporate governance and the general public. Network theory and elite studies are the two most prominent approaches to studying corporate elites and their connections. Since the early 1970s,

Elena Semenova

elena.semenova@fu-berlin.de

1 Institute of Political Science, Free University of Berlin, Ihnestr. 21, 14195 Berlin, Germany 
increasing attention has been given to the emergence and structure of corporate networks in Western Europe and the United States (Fennema and Schijf 1978). A particular focus of these studies was the connections between different enterprises in the form of interlocking directorates - that is, when the same individual serves as a member of the boards of directors of two or more companies. Researchers have identified that in the 1970s and 1980s, European and the US corporate networks were very dense across various industries and financial organizations (Scott 1991; Stokman et al. 1985). However, since the early 1990s, scholars have increasingly identified the segmentation of networks and the emergence of new modes of coordination within corporate environments in Europe and the United States (e.g., Beyer 2003; Beyer and Höpner 2003; Bühlmann et al. 2012; Heinze 2004; Heemskerk 2007; IJCS 2012).

The German case is no exception to this trend. Researchers have emphasized that interlocking directorates between industrial companies and financial institutions were one of the major features of the Deutschland AG ("Germany Inc."), a corporate model that dominated until the early 1990s (Albach and Kless 1982; Entorf et al. 2009; Pappi et al. 1987; Streeck 1997; Windolf and Nollert 2001; Ziegler 1981).

Studies that address interlocking directorates in the post-Deutschland AG period (i.e., the period since German reunification and its integration into European and global markets) have also noted changes to the German model of corporate governance. Most apparent indicators were the segmentation of networks between German industries and long-term banks and the decreasing density of company ties (Beyer 2003; Höpner and Krempel 2006; Windolf and Nollert 2001; Heinze 2004; Kengelbach and Roos 2006).

Although providing many valuable insights about the structure of networks across various industries and between industries and financial organizations, studies on interlocking directorates have ignored the individuals behind these networks. Does it matter who is sitting on the board, and what is this person's background? For studies on interlocking directorates, the answer to this question will be negative because such research is only interested in the structure of corporate networks at the level of companies.

Another dominant tradition in studying corporate power, elite studies, focuses on individuals and their backgrounds, e.g., the CEOs of the largest companies (Mills 1956; Bourdieu and de Saint Martin 1978; Hartmann 1996, 2018). Elite researchers have extensively examined the channels through which corporate leaders are recruited to their positions, the determinants of their tenure and the effects of internationalization on the formation of corporate elites (e.g., Bühlmann et al. 2012, 2017; Davoine and Ravasi 2013; Maclean et al. 2014). These studies have revealed, among other findings, that except for the United States, women rarely lead large corporations; that in some countries (e.g., the United Kingdom and France), the vast majority of CEOs have graduated from a small number of elite universities; and that in-house careers (i.e., the gradual career promotion of CEO candidates within a single company) have been an essential feature of German and Japanese corporate culture (for an up-to-date literature review, see Hartmann 2018). 
Both traditions (i.e., interlocking directorates and elite studies) provide insights into the structure of corporate networks. However, there are also gaps in the literature that are crucial to fill. The studies on interlocking directorates ignore the role of individuals in the emergence of corporate networks. Moreover, these studies have focused on strong ties (or embedded and frequent contacts) established through membership in different boards (Kirchmaier and Stathopoulos 2008, p. 9), while overlooking affiliation ties among elites emerging through societal clustering, for example, through joint attendance at the same university. In their turn, elite studies highlight the importance of social clustering and the value of individual experiences for entering corporate positions but neglect the importance of a network position these individuals occupy. For elite studies, it does not feel important whether specific CEOs are well-integrated into the overall corporate network or whether they have a particularly important brokerage position.

In this paper, I aim to fill these gaps in the literature and contribute to the debate on the development of corporate networks in the post-Deutschland AG period. Using a sample of chief executive officers (CEOs) from the 100 top companies in Germany in the 2010s, I look at an aspect of corporate networking that has been overlooked in existing studies, despite its apparent significance: the small-world network among top German CEOs measured through affiliation ties that have emerged from the CEOs' memberships in different societal groups (i.e., university, co-worker, nonprofit organizational, and policy organizational ties). For this purpose, I employ the instruments of social network analysis (Borgatti et al. 2002) and recent research on network topography in complex systems that emphasizes the random nature of ties (Watts and Strogatz 1998). This analysis addresses this blind spot in the existing research by analyzing various kinds of affiliation networks among German CEOs and providing a broader and more nuanced look at changes in affiliation networks and their small world character.

This paper also contributes to elite studies and their research on corporate elite selection and careers. However, rather than examining the aggregate patterns of selection and careers of corporate elites (see, e.g., Freye 2010; Hartmann 2018), I provide evidence of specific connections between corporate recruitment patterns and the structure of affiliation networks in Germany. For this purpose, I use multiple correspondence analysis (MCA), which helps to identify the recruitment patterns specific to subgroups within the corporate network.

This article consists of five sections. After this short introduction, I will present the theoretical backgrounds of this article and formulate hypotheses. The third section describes my data and explains the benefits of applying a mixedmethod design for studying CEOs' networks in Germany. The fourth section presents an empirical analysis of a variety of affiliation networks among the nation's top CEOs. After identifying subgroups within the overall corporate network, I show the linkage between the specific features of their recruitment and their positions in the affiliation network. After a discussion of the results of the analysis in the fifth section, I conclude with a section that reviews the insights gained from looking at the forms of networking that have emerged within Germany's corporate environment. 


\section{Affiliation networks of CEOs: theory and hypotheses}

\subsection{Function of networks}

Granovetter $(1973,2005)$ argues that social networks are essential for three reasons: they affect the obtainment and quality of information, act as an instrument of reward and punishment, and build trust among members of the network. Using his theory, researchers have discovered the characteristics of these ties in corporate networks (e.g., Larson 1992; Mariotti and Delbridge 2012; Knoke 2018). For example, studies have revealed that dense networks characterized by repeated and prolonged connections (strong ties) facilitate the exchange of highly complex knowledge, create shared values and trust, and foster reciprocity (Uzzi 1997; Nahapiet and Ghoshal 1998). Less dense networks, which are built on irregular and more distant connections (i.e., weak ties), in contrast, are more effective in acquiring innovative knowledge, avoiding redundancy, and building bridges between separate actors (Burt 1992). New information-including employment opportunities - is more likely to flow through weak ties (Granovetter 2005). Moreover, networks based on weak ties influence a company's performance, the CEO's compensation, and the CEO's behavior (e.g., Hwang and Kim 2009; Brown et al. 2012; Chidambaran et al. 2011).

\subsection{The 'Small world' model and affiliation networks}

Granovetter's $(1973,2005)$ distinction between weak and strong ties is based on the perception that people know each other personally (i.e., strong ties as regular and emotionally intense contacts, and weak ties as irregular and distant connections). However, as Mills (1956) pointed out, members of the corporate elite all seem to know one another, even without any personal contact. How is that possible, theoretically, and practically?

Milgram (1967) answered this question by maintaining that any one person in the world could be reached through a network of acquaintances in only a few steps. This assumption is known as the "small world problem." Travers and Milgram (1977) have shown experimentally that randomly selected individuals in Nebraska and Boston are able to reach a target person in Massachusetts in approximately six steps. This finding became a piece of popular knowledge referred to as 'six degrees of separation.'

Milgram's model was developed by Watts and Strogatz (1998), who have proven that real-world networks are neither completely structured nor completely random, but rather contain essential features of both. These properties can be described through the clustering coefficient (a measure of the local density of the network) and the average shortest path length (a measure of separation). The difference between random graph networks and real-world networks is that the latter are characterized by a shorter average distance between pairs of actors than in random graphs of the same size. Moreover, most actors live in local neighborhoods where most other 
actors are also connected to one another. In other words, the clustering in real-world networks tends to be higher than in random graphs of the same size.

Affiliation (or bipartite) networks are one of the examples of a network with small-world properties, assuming that actors choose their groups to affiliate with at random (Newman et al. 2002). Because two actors are connected whenever they share a group (e.g., a university or work place), the single-mode network of individuals exhibits many overlapping cliques that contribute to a high local clustering of the overall network. Moreover, bipartite networks virtually always have short global path lengths (Watts 2004).

How can members of a small-world network find each other? Kleinberg (2000) argues that small-world networks are searchable; in other words, not only are there short paths between randomly selected individuals in the large population, but these individuals can also locate these paths using their local information about the overall network. Watts et al. (2002) argue that this searchability is based on the individuals' identities (i.e., sets of characteristics attributed to them because of their association with social groups). Participation in certain social groups not only defines individual identity but is also a primary basis for establishing a tie. The most fundamental social dimensions used by individuals are geography and occupation (Watts et al. 2002, p. 1303). This model was tested in a Web-based experiment conducted by Dodds et al. (2003), in which they replicated Milgram's experiment with 18 targets in 13 various countries and found out that successful social search in the networks occurs through weak ties and predominantly rely upon geography and professional relations. Dodds et al. (2003) confirmed the average global path length of 5-7 steps between social searchers and their targets.

If anyone in the world can be reached in 5 to 7 steps, how about affiliation networks among those who managed to be promoted to the leadership position of one of the 100 largest companies in Germany? This is not just a small world but a small group population. Based on Watts's work (2004), I expect, therefore, that

Affiliation networks of German CEOs will show the small-world properties, i.e., a high clustering coefficient and a short average path length (H1).

\subsection{Types of affiliation networks}

As Dodds et al. (2003) have revealed, affiliation networks are primarily structured according to two social dimensions: geography and occupation. Based on these dimensions only, each one in this group could reach another in a very few steps. The country of birth of the respective CEO is an essential element of the geographic dimension as it relates to the corporate culture, traditions, and values that the CEOs have experienced during their personal and professional socialization. Previous studies have shown, among other things, that corporate culture differs from country to country substantially: from the open recruitment characteristic of Anglo-Saxon countries to the closed ('gang') recruitment system characteristic of post-Soviet countries of the early 1990s (Egan 1997; Stephenson 2015). Based on studies of corporate culture, I expect that 
The networks of the CEOs born in Germany will have a higher density than the networks of the CEOs born in other countries because the former have had more opportunities to build new ties throughout their career (H2).

The occupational dimension of the small-world network of German CEOs includes three main elements. The first is the industrial sector in which the manager was employed before assuming the current CEO position. The development of modern societies follows the path of segmentation and functional differentiation. Organizational differentiation leads to the development of specific types of organizational culture (Chatman and Jehn 1994), which tend to vary more across industries than within industries (Tsui et al. 2006). Networks that emerge within the same industry share common characteristics and interests (e.g., Bourdieu 1986, 1996; Bourdieu and de Saint Martin 1978). Researchers have shown, for instance, that CEO succession usually occurs via intra-industry recruitment because CEOs in each industry share a set of non-transferable managerial skills (Zhang and Rajagopalan 2003). Engelberg et al. (2013) have shown that a CEO's compensation is higher if they have many contacts within the same industry. Based on research that analyses common background and shared interests among corporate elites (e.g., Bourdieu 1996), I expect that

German CEOs' industry-specific networks have a high density (H 3).

The second element of the occupational dimension is the ties that emerge from co-working experience in the same organization (Granovetter 1973, 2005). International studies have shown that a common employment background likely facilitates the exchange of social support and establishes trust (McDonald and Westphal 2003), decreases the probability of financial fraud conducted by a given company (Chidambaran et al. 2011), and positively affects the amount of compensation a CEO receives (Brown et al. 2012).

I expect that, in the German context, co-worker connections are one of the most crucial affiliation networks because the typical German managerial career usually means slowly climbing the corporate ladder within one single company (Hartmann 1956, 1996). Although scholars have disagreed about the persistence of this pattern in the post-Germany AG period (e.g., Gergs and Schmidt 2002; Freye 2010), there is a consensus that in-house careers are a specific feature of the German corporate recruitment market (Egan 1997; Windolf 2003). Based on this literature, I expect that

Co-worker affiliation networks among the nation's top CEOs will have a high density ( $H$ 4).

The third element of the occupational dimension is the CEOs' alumni affiliation networks (i.e., when CEOs studied in the same university). Scholars have found that alumni ties may decrease the CEO's probability of being dismissed (Plian 1995) but also make the CEOs more ignorant toward market reactions regarding possible acquisitions of companies (Chikh and Filbien 2011) and even increase the company's probability of committing financial fraud (Chidambaran et al. 2011).

Because the German educational landscape differs from that of the United States or France, where it matters whether a CEO studied at Harvard, or one of the Grandes Écoles, some researchers argue that this connection plays no role in the German context. For example, Hartmann (2018, p. 405) has argued that "even 
though some 38 percent of German CEOs have attended only ten universities, one in five German students was enrolled at one of these universities at the time those CEOs attended them". However, Hartmann's argument demands two adjustments. First, traditionally, German managers have educational backgrounds in the technical and natural sciences (Hartmann 1956, 1996; Gergs and Schmidt 2002; Windolf 2003); therefore, the probability of establishing a tie through alumni connections between the CEOs of the largest German companies is not negligible. Second, Hartmann's argument is based on the concept of strong ties and suggests that only direct (or face-to-face) contacts constitute a tie, which is essential to the emergence of networks. Based on Watts and Strogatz's scholarship (1998), I expect that 5).

the German CEOs' alumni affiliation networks will have a moderate density (H

Although Watts et al. (2002) and Dodds et al. (2003) have emphasized the pivotal importance of geography and occupation in structuring the small-world network, these dimensions are often supplemented by myriad other types of social clustering. With his theory of different types of capital (1986, 1996), Bourdieu highlights the significance of social capital as a set of social obligations for structuring the world of elites. This set of social obligations can be acquired during the managers' charitable work and through memberships in various organizations (e.g., Bourdieu and de Saint Martin 1978; Bourdieu 1996). In contrast to geography, which the manager is unable to choose, and occupation, which results from both abilities and luck, the manager's involvement in charity and policy organizations is a nonrandom choice. For example, studies of philanthropy have revealed that CEOs strategically choose charity organizations and contribute to those addressing particular social issues that will benefit the company's business position (Saiia et al. 2003). Based on this literature, I expect that

CEOs' affiliation network based on membership in charity organizations will have a high density ( $\mathrm{H} 6$ ).

CEOs' participation in policy organizations takes different forms-from professional networks (e.g., organizations of one specific branch) to producer networks to specific issue networks (compare Rhodes 1990). Research has shown that these networks serve as channels of communication and methods for the exchange of information, trust, and other policy-relevant resources (for the literature review, see Knoke 2018; Kenis and Schneider 1991, pp. 41-42).

In Germany, a significant body of the literature deals with policy networks, in which CEOs of the largest companies participate, including different types of lobbying, government relations, and professional organizations (e.g., Schörner 2017). Politically, policy organizational networks became particularly important after German reunification because these networks were entrusted with the privatization of former GDR enterprises through the 'Treuhandanstalt' (Trust Agency). Because German society holds a negative perception of revolving doors between politics and big business (Klein and Höntzsch 2007), I expect that German CEOs will prefer to join policy organizations and that

The CEOs' affiliation network based on the membership in policy organizations will have a high density ( $H$ 7). 


\section{Methods and data}

\subsection{Data}

The companies analysed in this article are taken from a list of the 100 largest companies in Germany, annually published by the Frankfurter Allgemeine Zeitung (FAZ). The CEOs of the selected companies were identified by checking the respective company reports. Other sources of information used include the Munzinger database, issues of Wer ist Wer? (the German Who's Who), information provided by the companies, and newspapers. In total, data were collected and coded for 100 individuals regarding their career paths (if possible, since their university education) and the networks in which they were active before assuming a CEO position in one of the top companies. The cross-sectional data set includes two observation points-the years 2012 and 2015.

\subsection{Combining the social network analysis and multiple correspondence analysis}

Social network analysis (SNA) is a quantitative method for assessing the character of elite groups in various institutional settings (Scott 1991). Mapping elite networks is a powerful tool for understanding how elites are structures, how elite subgroups interact, and how their networks change over time. I use this method because it is the most suitable for identifying how the overall small world network in Germany is structured and what is the importance of specific affiliation networks to the density of the overall network.

In its turn, Multiple Correspondence Analysis (MCA) focuses on actors participating in the corporate network and their backgrounds. Being a multivariate method, MCA combines information from a set of background information coded in the form of nominal variables, which it presents as a relational graph. The graph shows the cloud of individuals and the cloud of categories (usually in two-dimensional space). Variables situated closer on this graph means that many individuals share the characteristics that were captured by the variables (Bourdieu and de Saint Martin 1978).

In sum, SNA focuses on the ties between members of a corporate elite and allows one to determine the cohesion or fragmentation of the small world network of German CEOs. This methodological approach, however, overlooks individuals behind this network, their backgrounds, and careers. MCA compensates for this shortcoming by systematically introducing the actor's characteristics into the analysis (e.g., Bourdieu 1996). The novel contribution of this study is that I take into account the affiliation network characteristics of each CEO and systematically connect them to their recruitment and career paths. It allows us to better understand the effects of individual backgrounds and networks on the structure of a small-world network. 


\subsection{SNA: small world analysis}

Watts and Strogatz (1998) discovered that in contrast to random graphs, observed social networks (e.g., affiliation networks) have a higher clustering coefficient (i.e., the average density of all neighborhoods) and a shorter average path length among actors. A small world model assumes that a network consists of $n$ nodes (CEOs) and a mean of $k$ affiliation ties among them. The average path length $\left(L_{\text {network }}\right)$ is the average of all shortest path lengths between nodes in the largest component. ${ }^{1}$ The clustering coefficient $C_{\text {network }}$ describes the average degree of local clustering in the largest component; in other words, it represents the extent to which CEOs that share affiliation ties with a focal CEO also share affiliation ties with one another. In order to identify whether the affiliation networks analyzed in this article have small-world features, their characteristics will be compared to a random graph of the same size. For this random graph, $L_{\text {random }}$ will be the average path length in the largest component (approximated $\ln (n) / \ln (k)$ ), and $C_{\text {random }}$ will be the average degree of local clustering (approximately $k / n$ ). Finally, the small-world coefficient will be calculated using the following formula: $\left[C_{\text {network }} / L_{\text {network }}\right] *\left[L_{\text {random }} / C_{\text {random }}\right]$; it should be substantially $>1$. It was found that networks with small-world features range from extremely small (the brain of the worm C. elegans; Watts and Strogatz 1998) to extremely large (the World Wide Web; Barabasi 2002).

\subsection{SNA: operationalization of ties}

I study six types of affiliation ties among CEO candidates based on the individuals' social identities. The first type of affiliation networks is the country of the CEO's birth, which is related to the geographic dimension of the small-world network. Three types of ties are related to the occupational experience of the candidates before their recruitment: industry-specific ties (i.e., ties emerged from the occupational activity in the same branch of industry), alumni-network ties (e.g., education at the same university or participation in the same vocational training) and co-worker ties resulting from working experience in the same company (or in the same company group). In addition to looking at affiliation ties based on shared occupational experience, I examine two types of ties based on policy-relevant networks through which the candidates connect with colleagues across companies and economic sectors. These include connections through membership in charity organizations (e.g., the advisory board of a university or a non-profit foundation) as well as ties through membership in policy organizations (including think tanks).

\footnotetext{
${ }^{1}$ Degree centrality measures the importance of a node (in our case, a CEO) based on the number of ties held by each node. Like degree centrality, eigenvector centrality measures a node's influence based on the number of ties it has to other nodes in the network. It also takes into account how well connected a node is, and how many ties their connections have (i.e., it measures how well the node is connected and whether it is connected to another well-connected node). Betweenness centrality measures the number of times a node lies on the shortest path between other nodes (i.e., whether the node has a brokerage position in the network). Components are portions of the network that are disconnected from each other. For more details, see Knoke and Yang (2020).
} 
All ties are measured as binary variables (absent or present). This measure does not produce a systematic bias that would impact a study of the overall structure of the affiliation network (Keller 2018). In this study, I am not interested in the strength of the connection between CEOs (e.g., whether they used to have a strong connection in the past, which weakened recently, or whether they used to have a potential tie; Mariotti and Delbridge 2012). For the research question this article poses, the absence of these qualitative measures will not bias the results because I do not expect any of them to be systematically related to the structure of the German smallworld network I investigate in this study.

There are two possible critiques of this operationalization of ties. The first is that these networks are of low importance compared to those of interlocking directorates. Watts and Strogatz (1998) highlight that both strong ties (e.g., interlocking directorates) and affiliation ties established through membership in different social groups contribute to local clustering of the overall network structure. Therefore, affiliation networks are a vital aspect of the overall corporate structure, which complements interlocking directorates, and thus must be examined.

The second critique is that many ties (e.g., alumni or co-worker ties) are less important than more recent connections. However, research has identified that for mapping the corporate network, using recent connections only produces an underestimation of the network (Kirchmaier and Stathopoulos 2008; Brown et al. 2012).

For social network analysis, the data collected on the recruitment of German CEOs were coded in a format that facilitates analysis using UCINet software (Borgatti et al. 2002). The connections between the CEO candidates were coded as present or absent (using binary variables) if two candidates had gained experience at the same organization (e.g., the same company). The shortcoming of this coding is that the direction of the ties (i.e., whether the candidates knew each other equally or one had more knowledge of the other) and the strength of ties (i.e., whether the connection was friendly) were not taken into account. Although this information may provide additional insights into the value of networks for the recruitment of German CEOs, its collection involves the use of surveys of elite members, which entails considerable time and resources and may lead to systematic bias in the selection of respondents.

\subsection{MCA: operationalization of variables}

For the collection of individual-level information on CEOs, I followed the example of studies on corporate elites in Europe (e.g., Hartmann 1996; Bühlmann et al. 2012, 2017). I coded individual information in three sets of variables. The first set includes demographic information about each CEO captured in four variables (compare, Hartmann 1996, 2018; Freye 2010). One variable coded information about whether the $\mathrm{CEO}$ has an advanced degree ('Secondary education,' 'BA/MA,' and 'Ph.D.'). Because CEOs with MBA degrees were almost absent in the 2012 sample, the variable 'MBA' was included only in the 2015 analysis. The second variable captures the type of education a manager received ('Economy,' 'Technical and natural sciences,' and 'Law'). The third variable included in the analysis was the CEO's age, which 
distinguishes among managers who are younger than 50 years old ('40/49'), in their fifties ('50/59'), and over sixty ('60/70'). The fourth variable was the origin of the $\mathrm{CEO}$, that is whether the CEO is German-born or a foreigner ('German-born' and 'NonGerman-born'). Because female CEOs are virtually absent from both samples, gender is not included in the analysis.

The second set of variables describes the CEOs' professional experiences (Freye 2010; Hartmann 1996; Windolf 2003). The first variable captures the sector to which the company led by the CEO is appertained ('Sec_Car and technical engineering,' 'Sec_Chemistry,' 'Sec_Energy,' 'Sec_Logistics/IT/finance,' and 'Sec_trade'). The second variable is whether the CEO had professional experience abroad ('ExpAbroad' and 'NoExpAbroad'). The third is the position from which the CEO was drawn, which distinguishes between the CEO or Vice-CEO positions ('CEO_prev'), members of the executive boards ('MemExecBoard_prev'), members of the supervisory boards ('MemSuperBoard_prev') and other positions including owners of the enterprises ('Other_prev').

The primary assumption of MCA is that the elite consists of different subgroups with their specific interests and ways of behaviour and thinking (i.e., habitus; Bourdieu and de Saint Martin 1978). A relational graph produced by MCA compels researchers to think about changes to the network structure as a consequence of conflict between these subgroups. However, analysis of the social characteristics of the actors ignores the interpersonal relations (De Nooy 2003), which are as crucial to understanding corporate networks as the recruitment patterns of its members.

Because I aim to show the connection between specific characteristics of managers and the structure of the small-world network in Germany, three affiliation network-specific variables (i.e., degree, eigenvector, and betweenness measures for each CEO $)^{2}$ were calculated from the overall 2012 and 2015 affiliation networks (see the next section) and included in the analysis. The normalized degree characteristic of each CEO was grouped into three categories: 'deg_low' (for degree values below 0.1), 'deg_mid' (for degree values between 0.1 and 0.2), and 'deg_high' (for degree values above 0.2). Similarly, the values of the eigenvector for each CEO were grouped and included in the analysis ('eig_low,' 'eig_mid,' and 'eig_high'). The normalized values of betweenness were also grouped into three categories: 'bet_ low' (for values of betweenness below 0.01), 'bet_mid' (for values between 0.01 and 0.05), and 'bet_high' (for values above 0.05). The grouping of these valuables was based on analysis of the distribution of normalized values.

The MCA used in this study excludes missing information while calculating the distances between individuals. All variables defined above contributed to the creation of the space. The importance of dimensions (defined as eigenvalue) was used to determine the number of dimensions to be interpreted. As recommended in the statistical literature (LeRoux and Rouanet 2010), I will explain both dimensions in detail, and then provide a general interpretation of the space.

\footnotetext{
2 See Footnote 1.
} 
Table 1 Characteristics of affiliation networks of German CEOs. Source author's own calculations

\begin{tabular}{|c|c|c|c|c|c|c|c|c|c|c|}
\hline & \multicolumn{2}{|c|}{$\begin{array}{l}\text { Alumni net- } \\
\text { work }\end{array}$} & \multicolumn{2}{|c|}{$\begin{array}{l}\text { Co-worker } \\
\text { network }\end{array}$} & \multicolumn{2}{|l|}{ NGOs } & \multicolumn{2}{|c|}{ Think tanks } & \multicolumn{2}{|c|}{$\begin{array}{l}\text { Whole net- } \\
\text { work }\end{array}$} \\
\hline & 2012 & 2015 & 2012 & 2015 & 2012 & 2015 & 2012 & 2015 & 2012 & 2015 \\
\hline Density & 0.018 & 0.016 & 0.040 & 0.019 & 0.006 & 0.002 & 0.073 & 0.048 & 0.107 & 0.083 \\
\hline Av. degree & 1.407 & 1.660 & 3.160 & 1.880 & 0.444 & 0.180 & 5.802 & 4.800 & 8.543 & 8.180 \\
\hline Degree centralization & 0.059 & 0.097 & 0.203 & 0.063 & 0.046 & 0.029 & 0.233 & 0.229 & 0.249 & 0.235 \\
\hline Components & 48 & 62 & 21 & 45 & 71 & 95 & 27 & 60 & 10 & 16 \\
\hline Connectedness & 0.046 & 0.036 & 0.494 & 0.064 & 0.006 & 0.002 & 0.442 & 0.150 & 0.789 & 0.704 \\
\hline Fragmentation & 0.954 & 0.964 & 0.506 & 0.936 & 0.994 & 0.998 & 0.558 & 0.850 & 0.211 & 0.296 \\
\hline Compactness & 0.029 & 0.025 & 0.196 & 0.036 & 0.006 & 0.002 & 0.220 & 0.095 & 0.386 & 0.327 \\
\hline$N$ & 9900 & 9900 & 9900 & 9900 & 9900 & 9900 & 9900 & 9900 & 9900 & 9900 \\
\hline
\end{tabular}

\section{Empirical analyses of affiliation networks of German CEOs}

\subsection{The geographical and occupational dimensions of the affiliation networks}

Analysis of affiliation networks based on the geographical dimension (i.e., the CEO's country of birth) has shown that the network density ${ }^{3}$ of CEOs born in Germany is slightly lower than that of CEOs born abroad ( 0.24 and 0.40 , respectively). Therefore, Hypothesis 2 was not supported. It appears that CEOs born abroad are more often engaged in various think tanks and policy organizations than their German counterparts. This engagement might be a strategy to compensate for the lack of affiliation networks based on occupational and alumni experience.

Regarding the small-world network's occupational dimension, alumni networks, which consist of ties based on shared university attendance, are low density (Table 1). In 2012, their density was slightly lower than $2 \%$. On average, each CEO had 1.5 ties within the alumni network. This 2012 network was characterized by low degree centralization and high fragmentation, as signified by a large number of components (i.e., portions of the network that are disconnected from each other), low connectedness and high fragmentation measures (Table 1). Although compared to 2012 , the average number of alumni ties in 2015 was slightly higher (1.6 ties), the density of the alumni networks had decreased slightly (Table 1). The number of components in the 2015 alumni network had increased, as had the fragmentation measure.

Interestingly, in both 2012 and 2015, the largest component of this network included alumni of five large German universities, four of which are situated in the North Rheine-Westphalia region: the RWTH Aachen, Ruhr-University of Bochum, University of Münster, and Cologne University. The fifth university was the Technical University of Munich (Bavaria region). In 2015, small groups of CEOs had

\footnotetext{
3 The density of a network is the proportion of all possible dyadic connections between actors that are actually present.
} 
Table 2 Density of the overall network within and across different branches of industry. Source author's own calculations

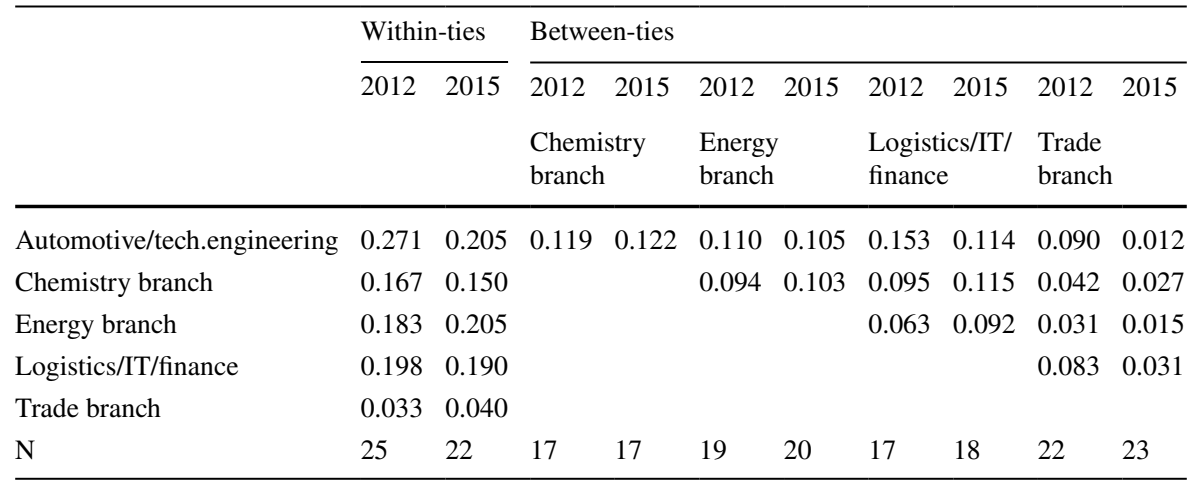

studied at the Karlsruhe University of Technology and the University of Stuttgart (Baden-Württemberg region).

In contrast to the alumni network, in 2012, the co-worker network (i.e., ties between those who have worked in the same company or corporate group) was denser (4\%). In 2012, CEOs had shared an average of 3.2 co-worker ties (Table 1) throughout their career. Degree centralization in this network was three times as high as in the alumni network. Compared to the alumni network, the co-worker network was better connected and less fragmented. In the 2012 co-worker network, moreover, the number of components (i.e., disconnected actors) was the lowest among all examined networks.

Among the networks studied, the massive drop in the density of the co-worker network was particularly impressive. In 2015 , the density decreased to $2 \%$ of all possible ties. The network became more fragmented, less connected, and less compacted than its counterpart in 2012 (Table 1). The degree centralization of this network also decreased. Although the densities of co-worker networks appear to be low, it is still noteworthy that the number of components in the co-worker network is the lowest of all of the networks (45 components) and that, over the course of their careers, German CEOs shared a working environment (a company or a corporate group) with a fellow CEO at least twice.

The density of industry-specific networks varied considerably (Table 2). ${ }^{4}$ In 2012, the density of networks within the automotive and technical engineering branch was the highest (27\%), while the density within the trade branch was as low as $3 \%$. The remaining branches had network densities of $17-20 \%$ of all possible ties (Table 2).

\footnotetext{
${ }^{4}$ In order to analyse networks of CEOs across different branches of industry, I built five groups that include enterprises industrially closed to each other. Each CEO was then assigned to one of five groups. The first includes CEOs leading enterprises in the automotive, electro- and transport engineering industry (hereafter, Automotive and technical engineering). The second group includes CEOs leading chemical enterprises (hereafter, Chemistry), while the third includes enterprises producing energy (hereafter, Energy). The fourth group contains CEOs heading companies in the area of logistics (e.g., train and plane companies), IT and finance (hereafter, Logistics/IT/Finance). Finally, the fifth group includes retail and wholesale trade (hereafter, Trade).
} 
In contrast, in 2015, network density in the automotive and technical engineering sector decreased slightly and was the same as in the energy sector (approximately $21 \%$ ). The density of networks within the trade industry remained the lowest (roughly 4\%).

This change in the density of the overall networks within different sectoral groups has implications for the density of between-group connections. In 2012, the density of between-group ties was the highest between the automotive and technical engineering branch and all other branches but trade. In contrast, networks of CEOs leading enterprises in the trade branch were the strongest with CEOs from the logistics, IT, and finance branches (Table 2). In 2015, the automotive and technical engineering branches remained best connected to all other branches, but trade and the density of between-ties among the automotive and trade branches even decreased to about $1 \%$. CEOs from the trade branch shared the highest number of connections with CEOs from chemistry and the logistics/finance/IT branches (around 3\% of all possible ties).

In order to assess the structural importance of individual CEOs, I analyze cliques ${ }^{5}$ existing within the overall affiliation network. These cliques are crucial for a better understanding of mobilization and diffusion as well as lines of cleavage within networks. Of all of the CEOs from the top 100 companies, the core corporate elite consists of 3 cliques (altogether, 23 CEOs). The density of these cliques was 13\%, with CEOs sharing all four types of affiliation ties among each other (Fig. 1).

The identified cliques consisted of CEOs from various branches of industries, with the highest representation of CEOs coming from the automotive and technical engineering branch (seven CEOs). The logistics/IT/finance branch was represented by six CEOs, while both the energy and chemistry branches had five CEOs each.

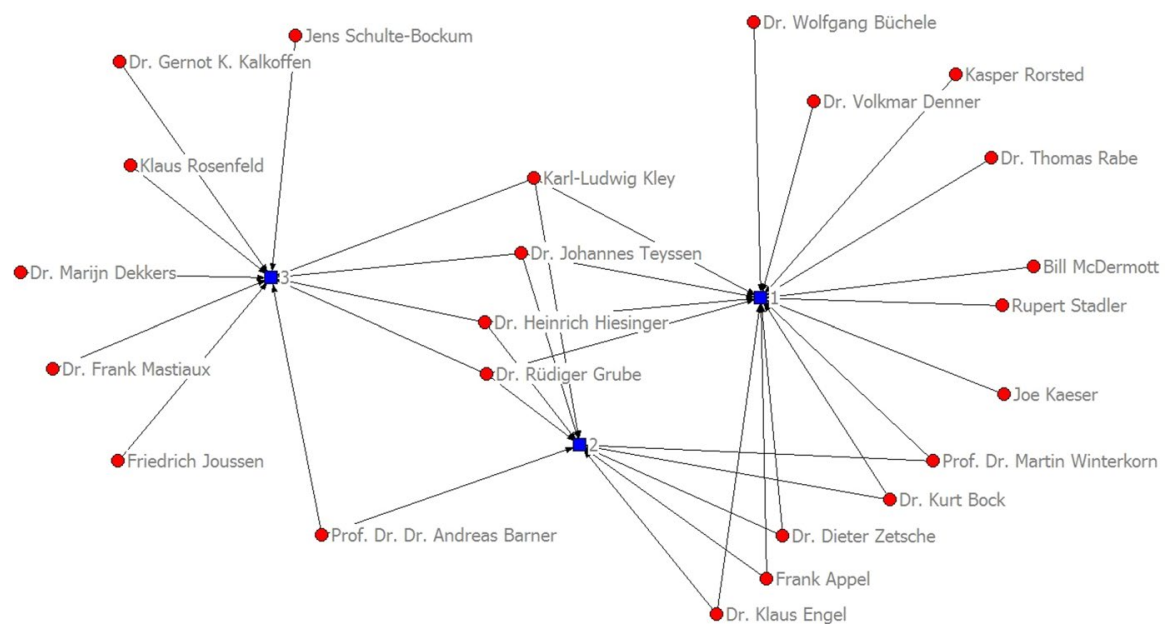

Fig. 1 Cliques within the overall affiliation network, 2015. Note rectangles are cliques, circles are CEOs. Source author's own calculations

5 A clique is the maximum number of actors who share all possible ties. 
The structure of cliques is particularly interesting. Five CEOs connected the first and the second clique: two from the automotive branch (Prof. Dr. Martin Winterkorn, Volkswagen and Porsche Automobil Holding, and Dr. Dieter Zetsche, Daimler AG), and one each from the chemistry (Dr. Kurt Bock, BASF SE), energy (Dr. Klaus Engel, Evonik Industries AG) and logistics industries (Frank Appel, Deutsche Post DHL). All of these CEOs had a high eigenvector of 0.24 (i.e., they were connected to other CEOs with a high- degree centrality within the overall network). The second and third cliques were connected by five CEOs. One of them, Prof. Dr. Andreas Barner (Boehringer Ingelheim, a leading German pharma enterprise), had a high betweenness value of 5.3, which suggests that he had an important brokerage position between two cliques.

The most important members of the 2015 core elite were, however, Karl-Ludwig Kley (Merck KGaA, one of the largest chemistry and pharma enterprises in Germany), Dr. Rüdiger Grube (Deutsche Bahn AG, the major transport enterprise in Germany), Dr. Heinrich Hiesinger (Thyssen Krupp AG, a large international concern specializing in industrial engineering and steel production), and Dr. Johannes Teyssen (E.on SE, one of the world's largest electric utility service providers). These five CEOs connected all three cliques, which was also shown by their extremely high betweenness value (25.3). They also had a very high eigenvector value of 0.31 , implying that they were connected to other members of this network with a high degree centrality.

In sum, industry-specific affiliation networks are the densest of all connections that constitute the small-world network's occupational dimension. This finding supports Hypothesis 3. CEOs from the automotive and technical engineering sectors occupy the dominant position in Germany's overall affiliation network. CEOs from the trade sector are virtually absent from the most central positions within the overall affiliation network. Alumni networks are essential to the structure of the affiliation network in Germany, but the magnitude of their effects is smaller than that of co-worker relations, as indicated by a higher density of co-worker affiliation networks compared to the network based on alumni ties. However, co-worker networks are the second-most dense networks compared to the German CEOs' industry-specific connections. Therefore, Hypotheses 4 and 5 were partly confirmed.

\subsection{Policy-relevant affiliation networks of German CEOs}

Examining policy-relevant networks (Table 1), I found that the density of ties within a single non-profit (charity) organization, for example, was even lower than that of the alumni network (in 2012, < 1\%). It comes as no surprise that this network was most fragmented and non-cohesive of all of the examined networks. The dissolution of the non-profit network was evident in 2015. The density of this network dropped even further; it became extremely fragmented, with the highest number of components (95). The average number of ties decreased from 0.4 (2012) to 0.2 (2015).

Out of all of the analyzed affiliation networks, the density of ties through participation in the same think tank or policy association is the highest. In the 2012 


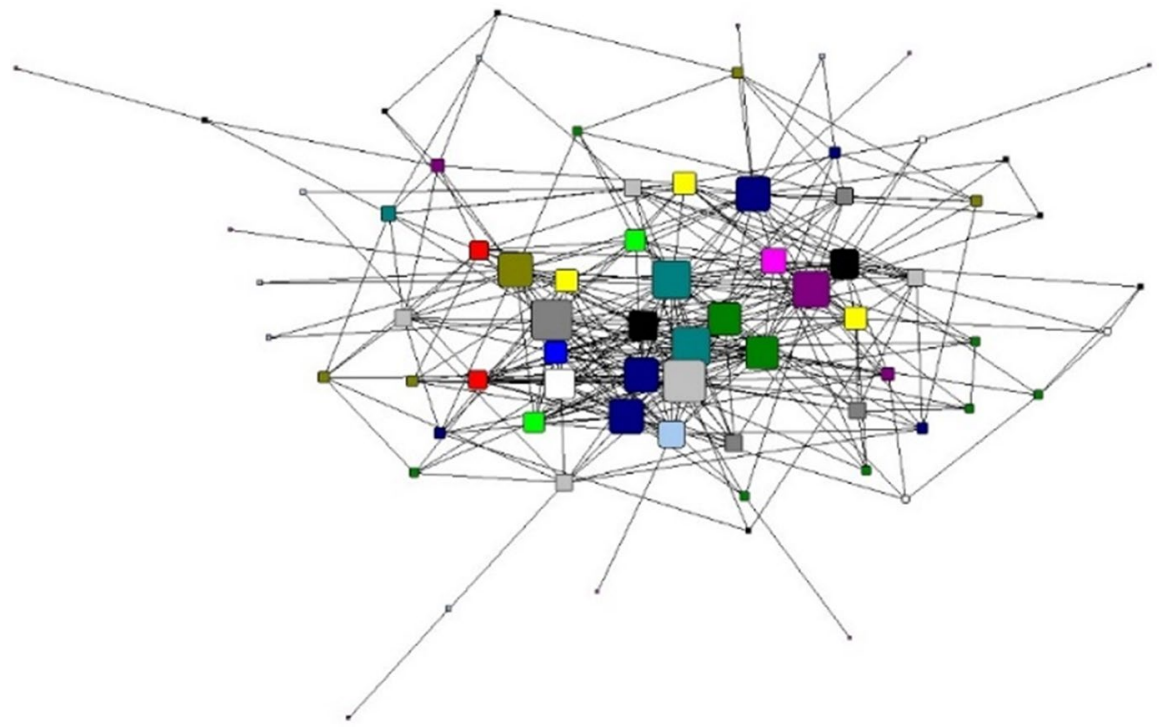

Fig. 2 The overall corporate network of German CEOs, 2012. Note isolates are removed, size of nodes are organized by the node's degree centrality. Source author's own calculations

think-tank network, its density was as high as 7\%, with CEOs sharing an average of 5.8 ties with other CEOs. This network was of the highest compactness, a relatively high connectedness, and the second-smallest number of components. In 2015 , the average number of ties decreased slightly to 4.8 ; the density of this network decreased to approximately 5\%. Compared to 2012, the network became less compact and more fragmented (Table 1).

In sum, ties through charity and other non-profit organizations have been of the lowest density among all examined in this study. Therefore, hypothesis 6 was not supported. Instead, policy organizational networks have the highest density among policy affiliation networks. It supports hypothesis 7. Among all affiliation networks examined in this study, only industry-specific affiliation networks are denser than policy affiliation networks.

\subsection{Affiliation networks of German CEOs: a small world?}

Combining all affiliation networks between German CEOs measured in this article reveals a dense overall corporate network in Germany. In the 2012 whole network (Table 1), the density was approximately $11 \%$, with an average of nine ties that each CEO shared with others. It was of high cohesion (as shown by the measures of connectedness, fragmentation, and compactness), with only ten components that were isolated from other parts of the network (Fig. 2).

Considering the decrease in the density of each network analysed, the lower density of the overall network in 2015 comes as no surprise (Table 1). The 


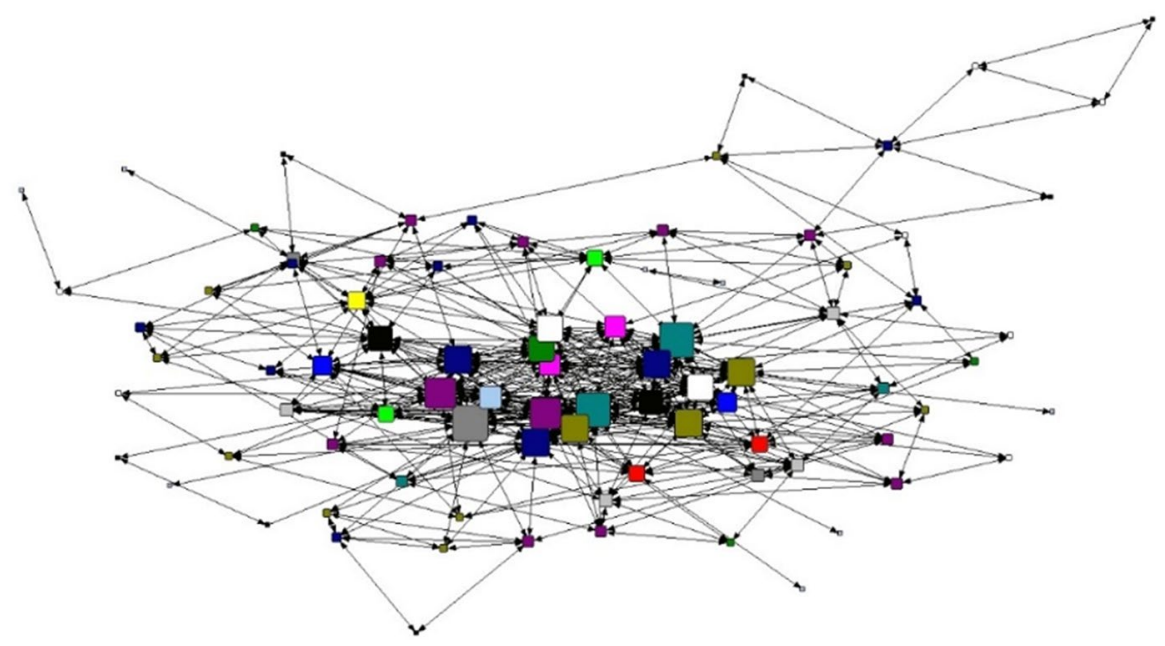

Fig. 3 The overall corporate network of German CEOs, 2015. Note isolates are removed, size of nodes are organized by the node's degree centrality. Source author's own calculations

Table 3 The overall affiliation network of German CEOs: a small world analysis. Source author's own calculations

\begin{tabular}{lll}
\hline & \multicolumn{2}{l}{ The overall network } \\
\cline { 2 - 3 } & 2012 & 2015 \\
\hline $\mathrm{N}$ overall & 100 & 100 \\
$\mathrm{~N}$ of the large component & 91 & 86 \\
Clustering coefficient $\left(\mathrm{C}_{\text {network }}\right)$ & 0.538 & 0.583 \\
The average path length $\left(\mathrm{L}_{\text {network }}\right)$ & 2.398 & 2.573 \\
Clustering coefficient $\left(\mathrm{C}_{\text {random }}\right)$ & 0.116 & 0.057 \\
The average path length $\left(\mathrm{L}_{\text {random }}\right)$ & 2.220 & 2.469 \\
Small-world coefficient & 4.287 & 9.833 \\
$\left(\mathrm{C}_{\text {network }} / \mathrm{L}_{\text {network }}\right) *\left(\mathrm{~L}_{\text {random }} / \mathrm{C}_{\text {random }}\right)$ & & \\
\hline
\end{tabular}

number of isolates (i.e., CEOs without any ties in any of the examined networks) increased from 2012 to 2015 (partly because of some fluctuation in German corporate leadership). The overall network has become less compact (with a density of $8 \%$ ), less centralized, and more fragmented (Fig. 3). The average number of ties has, however, decreased slightly (from 8.5 in 2012 to 8.2 in 2015).

In Table 3, the small-world analysis of the overall affiliation networks is presented. Both 2012 and 2015 affiliation networks can be counted as small-world networks, according to the small-world coefficient (4.3 in 2012 and 9.8 in 2015). Therefore, hypothesis 1 was supported. The average path length was 2.4 (2012) and 2.6 (2015). In both cases, there was a relatively high degree of clustering (Table 3 ). 
Table 4 The small world of the German CEOs (based on normalized betweenness scores). Source author's own calculations

\begin{tabular}{ll}
\hline 2012 & 2015 \\
\hline 1. Dr. Marijn Dekkers (0.110) & 1. Dr. Kurt Bock (0.111) \\
2. Karl-Ludwig Kley (0.080) & 2. Dr. Rüdiger Grube $(0.077)$ \\
3. Dr. Klaus Engel (0.074) & 3. Markus Mosa (0.071) \\
4. Frank Appel (0.060) & 4. Dr. Marijn Dekkers $(0.069)$ \\
5. Prof. Dr. Martin Winterkorn (0.053) & 5. Rene Plasman $(0.056)$ \\
\hline
\end{tabular}

As expected, the clustering coefficient of the real-world network (in our case, affiliation networks of German CEOs) is much higher than that of the random graph of the same size. In contrast, the average path lengths of both random and real-world networks are comparable. What is most striking is that the small-world statistics are very similar across both observation periods.

One possible explanation for this stability is that while CEOs in the affiliation network may come and go, few CEOs remain in their positions, creating short cuts among all the important CEOs happen to be at a given time. Table 4 includes the top five CEOs based on their betweenness measure. Only one CEO, Dr. Marijn Dekkers (Bayer AG), is among the top five in both observation periods. Among the top five of 2012, there were Karl-Ludwig Kley (chemistry; Merck KGaA), Klaus Engel (energy; Evonik Industries AG), Frank Appel (communication; Deutsche Post DHL), and Martin Winterkorn (automobile industry; Volkswagen AG). In 2015, apart from Marijn Dekkers, Kurt Bock (chemistry; BASF SE), Rüdiger Grube (transport; Deutsche Bahn AG), Markus Mosa (trade; EDEKA), and Rene Plasman (trade; Netto Marken-Discount) had the highest betweenness scores among all German CEOs. Many CEOs with high betweenness scores occupy important positions within the overall affiliation network, as our clique analysis has already shown (Fig. 1).

\subsection{Connecting networks and the recruitment patterns of German CEOs}

I conducted Multiple Correspondence Analysis (MCA) of actors participating in the small-world network and their individual background (e.g., age or the type of education). I also included the network indicators that describe the CEO's position in the overall affiliation network (i.e., degree, eigenvector, and betweenness measures). The analysis has revealed the existence of specific sub-groups in the German CEOs' affiliation network. The results are presented below (Figs. 4 and 5). The figures show the cloud of variables. In 2012, the first dimension (eigenvalue $=3.039$; variance $=30.4 \%$ ) described the differences in the network characteristics (i.e., degree and eigenvector), education, and professional experience of the CEO. On the right side of Fig. 4, one can find young CEOs (below 50 years old) who had either secondary education or a BA/MA degree in economics and finance. Often, these CEOs work in the trade sector and have had in-house careers. Their networks are of low density; they have few direct ties (degree) and often are not connected to the CEOs 


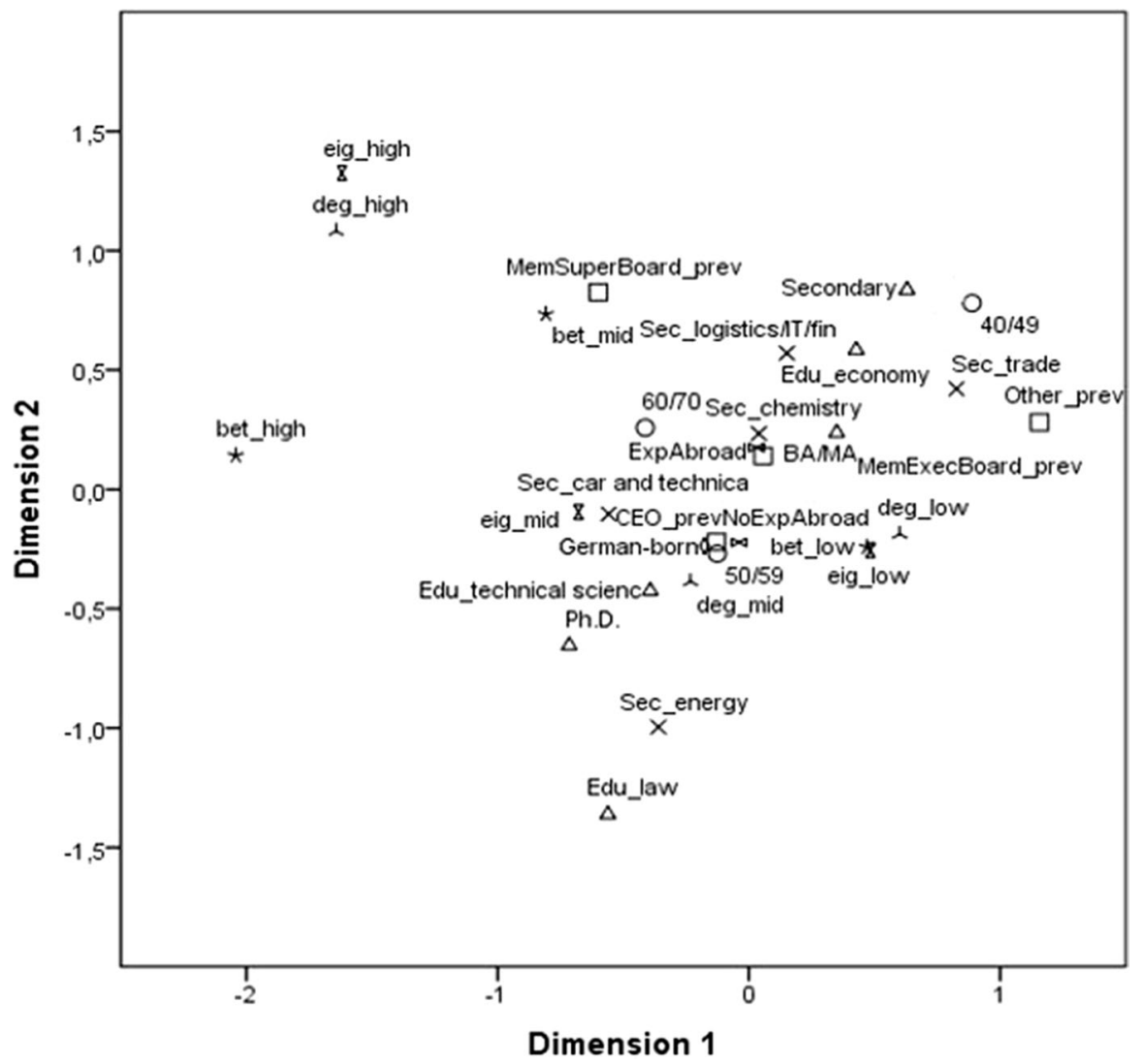

Fig. 4 The corporate space in Germany, 2012. Source author's own calculations

with a high number of direct ties (eigenvector). On the left side of the horizontal axis, one can find CEOs from the automotive and technical engineering sector who had studied technical and natural sciences, often had PhDs, and were usually in their fifties. These CEOs had a moderate number of direct ties (degree) and a moderate number of affiliation ties to other well-connected CEOs (eigenvector).

The second dimension (eigenvalue $=2.127$, variance $=21.3 \%$ ) describes the effect of internationalization on the network characteristics (in particular, on the betweenness of the CEOs). In the upper half of the Graph, one can find CEOs from the sectors of logistics/IT/finance and chemistry, who either had spent some years abroad or are foreigners. They were often drawn among members of supervisory boards. These CEOs have got important brokerage positions within the network, which is signified by the middle to high values of betweenness centrality. In the lower half of the graph, one can find CEOs with strong national connections, that is those from the energy sector, who studied law, were German-born, had gained executive experience (CEO or vice-CEO positions), and never worked abroad. The betweenness values of these $\mathrm{CEOs}$ were low. 


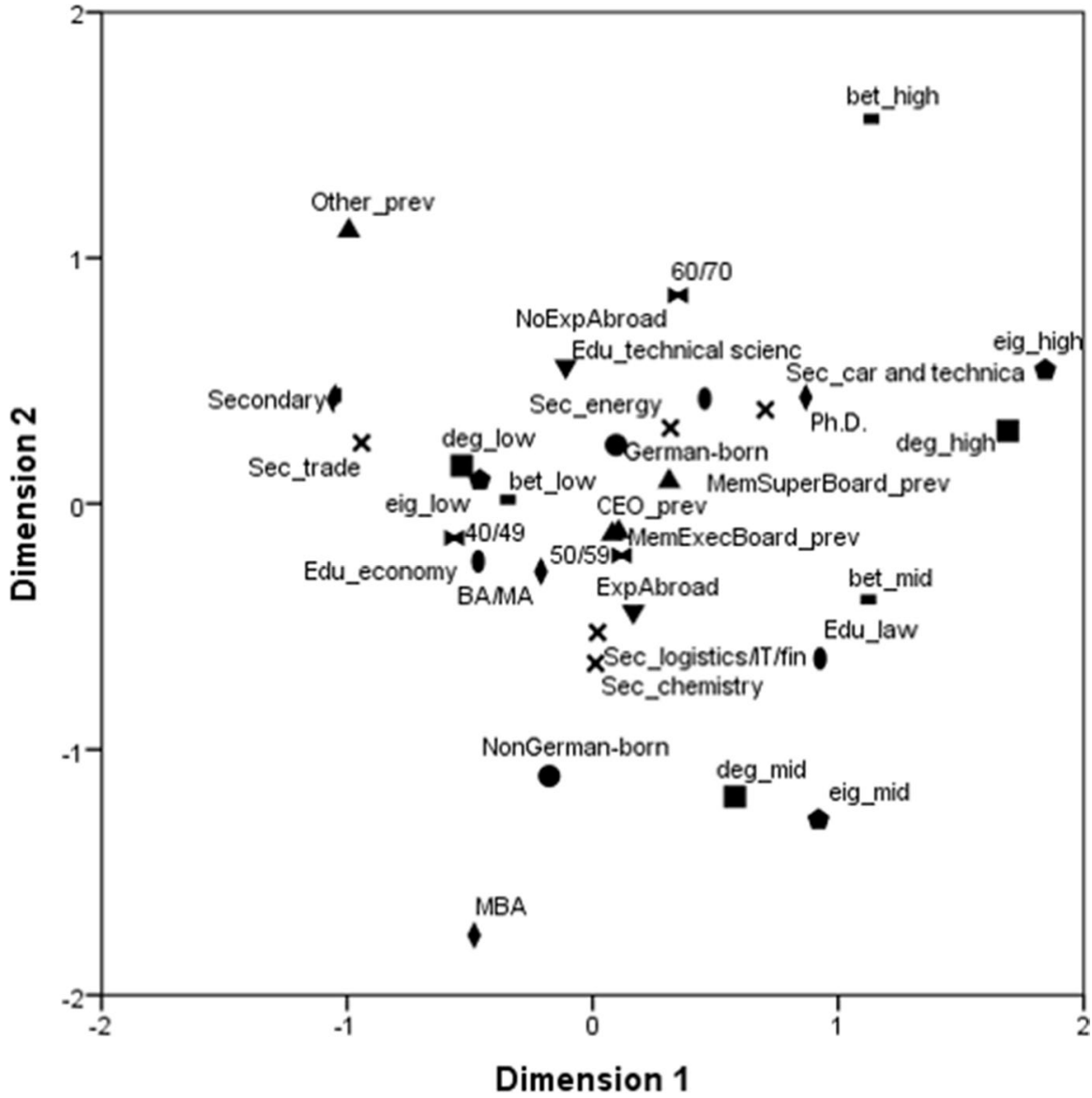

Fig. 5 The corporate space in Germany, 2015. Source author's own calculations

In general, the corporate network in 2012 consisted of three clusters of CEOs with specific educational and professional backgrounds. The first cluster includes CEOs from the trade sector (in the upper-right quadrant), who were young and not well integrated into the overall corporate network (low degree, betweenness, and eigenvector values). They had gained less executive experience before their recruitment than their counterparts from other branches and were often drawn from the position within the same enterprise in which they are currently CEOs (in-house careers). The second cluster (the centre of the graph) includes CEOs from industries with a high degree of technological complexity and internationalization: logistics/IT/finance and chemistry. CEOs from the former branch were usually drawn from among members of the executive board. CEOs from the chemistry branch usually gained executive experience as CEOs or viceCEOs abroad before their recruitment to the German enterprise. The third cluster includes CEOs from the automotive and technical engineering industry, who 
had strong national connections (the lower-left quadrant). These CEOs were often recruited from the same corporate group which they had led in 2012. The existence of three clusters (and a somewhat isolated energy sector) shows that the corporate space in 2012 was segmented along industrial network lines, with a prominent position of CEOs from the automotive sector.

In the 2015 sample (Fig. 5), the first dimension (eigenvalue=3.278, variance $=32.8 \%$ ) describes the difference between the membership in a specific sector, education, and network characteristics of the CEOs. On the right side of the graph, one can find CEOs from the automotive and technical engineering sector, who had $\mathrm{PhDs}$ and were exceptionally well integrated into the overall network (high normalized degree, eigenvector, and betweenness values). CEOs from the trade sector can be found on the left side of the graph. They often had only a secondary educational degree, were poorly integrated into the overall network (low values of all network characteristics), and lacked executive experience.

The second dimension (eigenvalue $=2.040$, variance $=20.4 \%$ ) describes the internationalization of the corporate space. On the upper side of the graph, one can find older CEOs, who lacked experience abroad. They were usually from the automotive and technical engineering as well as energy sectors. These CEOs, however, had an important brokerage position within the overall network (high betweenness values) and were also often connected to other powerful members of the corporate elite (high eigenvector values). In the lower half of the graph are CEOs from the most internationalized sectors of economy (i.e., chemistry and logistics/IT/finance). They had MBAs and had either worked abroad or were foreigners. Because of this, they were moderately well integrated into the overall network (intermediate values of degree, betweenness, and eigenvector).

Overall, there were three clusters of CEOs within the corporate space in 2015. The first cluster includes CEOs from the trade sector (in the upper-left quadrant). They had a low level of education. The proportion of these managers without any executive experience has been the highest among all examined branches (approximately 25\%). Moreover, the proportion of trade managers recruited from the same corporate group (i.e., those with in-house careers) fluctuated between 55 and $60 \%$, which is the second-lowest level among all branches. As a results, they were poorly integrated into the overall network (low degree, eigenvector, and betweenness values).

The second cluster (the upper-right quadrant) includes CEOs from the automotive and technical engineering and energy sectors, who were highly educated, German-born, and had gained experience as members of supervisory boards of other companies. Approximately $70 \%$ of CEOs from this branch were recruited from the same corporate group. These CEOs are the core elite of the overall network (with an extremely high degree and eigenvector values) and play a crucial brokerage role within the network (high betweenness values).

The third cluster (the lower-right quadrant) consists of CEOs from the chemistry and logistics/IT/finance sectors, who had gained working experience and executive experience both abroad and in Germany. While in the logistics/IT/ finance branch, the CEOs have been predominantly drawn from the members of the executive boards (more than 70\%), in the chemistry branch, the candidates 
Table 5 Dr. Marijn Dekkers' and Dr. Kurt Bock's distribution of "Degrees of Separation" in 2015. Source author's calculations

\begin{tabular}{lcllllll}
\hline Degree & \multicolumn{2}{l}{ Marijn Dekkers } & & & Kurt Bock & \\
\cline { 2 - 3 } & Frequency & $\%$ & Cumulative $\%$ & & Frequency & $\%$ & Cumulative \% \\
\hline 0 & 1 & 1.2 & 1.2 & 1 & 1.2 & \\
1 & 20 & 23.3 & 24.5 & & 29 & 33.7 & 34.9 \\
2 & 51 & 59.3 & 83.8 & & 44 & 51.2 & 86.0 \\
3 & 9 & 10.5 & 94.3 & & 9 & 10.5 & 96.5 \\
4 & 3 & 3.50 & 97.8 & & 1 & 1.2 & 97.7 \\
5 & 2 & 2.2 & 100 & & 2 & 2.3 & 100 \\
$\mathrm{~N}$ & 86 & 100 & & 86 & 100 & \\
\hline
\end{tabular}

must prove an executive experience as CEOs or vice-CEOs of other companies (approximately 60\%). Their position within the overall network is slightly less prominent compared to the position of CEOs from the second cluster (moderate degree, eigenvector, and betweenness values).

\section{Discussion}

\subsection{Small-world features of the affiliation networks of German CEOs}

This study is the first empirical work that shows the small-world character of the CEOs' affiliation networks in Germany. Each CEO can reach another CEO in approximately two steps, even without previous personal contact. Moreover, these affiliation networks have a substantially higher clustering than random graphs of the same size. These features of affiliation networks do not require any specific design; they stem from the network topography of complex societal systems.

In order to show the implications of the small world features of affiliation networks, the 'degrees of separation' for two CEOs with high betweenness scores (Marijn Dekkers and Kurt Bock) in the year 2015 were estimated (Table 5). The table implies that more than $80 \%$ of all German CEOs are within two degrees of separation, approximately $94-97 \%$ of all CEOs are within three degrees of separation, and only $2 \%$ are as far away as five degrees. Such short path lengths mean faster spreading of information, strategies, and innovations (Watts 2004).

\subsection{Affiliation ties of German CEOs}

Starting with policy organizational ties among German CEOs, the range of policy-oriented associations includes the Atlantik-Brücke (a private and non-profit 
organization with the goal of strengthening relations between the United States and Germany), various associations (e.g., of the German Automotive Industry Association) and various entrepreneurial organizations and think tanks, at both the national and the European levels. Active participation of top managers in various policy organizations has many advantages. It allows managers to establish ties within a single industry and across industries (Schörner 2017). Since the decline of Deutschland AG, policy ties have compensated for the decreasing connections within the corporate network.

Co-worker networks have been of a lesser density than policy organizational networks. These ties are an effective structural response to the heterogeneous structure of modern organizations (Granovetter 1973). CEOs tend to use networks for the realization of their business and career goals alike (Carroll and Teo 1996). The decline in the density of co-worker ties between two observation points may be a consequence of both structural and organizational developments. The primary structural reason is the internationalization of the business environment. The proportion of German CEOs who had gained working experience abroad (in this study, between 55 and 60\%) is high by the international comparison (compare, the CEO Success Study published by PricewaterhouseCoopers 2018). It is, therefore, possible that German CEOs are more engaged in international networks than in national ones. Among organizational reasons, a high volatility of corporate careers is essential. The average tenure of a German CEO has decreased to approximately 5 years (as an additional analysis has shown), which is short compared to their counterparts in other countries (compare, PricewaterhouseCoopers 2018). A massive turnover of managers contributed to a decrease in the density of co-worker networks, and, consequently, to a decrease in the overall density of networks in 2015.

Regarding the low density of alumni ties, the absence of elite universities may contribute to the lower number of the same university connections among German CEOs (compare, Hartmann 2018). The lower number of ties that German CEOs have established through joint membership in charity organizations may stem from a country-specific understanding of corporate responsibility. In contrast to the United States, where CEOs are expected to be engaged in various charitable activities (e.g., Saiia et al. 2003), German CEOs tend to rely on income redistribution and taxation as important instruments of support that replace the need for philanthropy (Fifka 2013).

However, German CEOs are not connected through one type of affiliation network. Based on the quadratic assignment procedure (QAP) correlation analysis (Krackhardt 1987), the analysis has shown a high correlation between the CEO's membership in one affiliation network and his membership in another one. For example, if the CEOs were connected through co-worker networks, they were also more likely to be connected through policy organizational ties. ${ }^{6}$ The engagement of two CEOs in the same NGO significantly correlated with participation in the same think tanks. ${ }^{7}$ Moreover, alumni and co-worker ties also correlated, but the effect size was negligible in both cases.

\footnotetext{
6 In 2012, Pearson's $\mathrm{r}=0.09, \mathrm{p}<0.01$; in 2015, Pearson's $\mathrm{r}=0.05, \mathrm{p}<0.01$.

7 In 2012, Pearson's $\mathrm{r}=0.16, \mathrm{p}<0.001$; in 2015, Pearson's $\mathrm{r}=0.08, \mathrm{p}<0.01$.
} 
What do these findings mean for the small-world analysis of German CEOs' affiliation networks? First, they support Granovetter's argument (1973) that sharing one type of affiliation ties increases a sense of trust and makes the establishment of further ties more probable. Second, these findings support the expectations derived from the small-world analysis (Watts et al. 2002; Dodds et al. 2003), according to which any connection between two actors contributes to the establishment of many overlapping cliques, which in their turn, contribute to a high local clustering of the overall network (Newman et al. 2002; Watts 2004).

\subsection{The linkage between networks and recruitment patterns}

The most crucial finding presented in this article is that German CEOs are most strongly connected through their industry-specific ties (i.e., the occupational dimension of the small-world networks) and their geographical networks (the geographical dimensions of the small-world networks). Multiple correspondence analysis reveals that the affiliation networks in Germany consist of groups of CEOs with distinct recruitment patterns that are connected by different types of affiliation ties. The first group of CEOs is managers from the automotive and technical engineering branch. They usually are Germans and hold PhDs in the technical and natural sciences. This group of CEOs exemplifies the dominance of technically educated managers in the corporate environment, which emerged in the early 1950s and continued even after the reunification of Germany (Hartmann 1996). Researchers have related this educational pattern to the German innovation regime (Hall and Soskice 2001) and the German type of capitalism (Streeck 1997), which have focused on the incremental technical innovation of high-tech products. ${ }^{8}$

CEOs from the automotive branch have been the best-connected both within their branch and between other branches of industry. The high density of their withinbranch networks stems primarily from their co-worker ties. This group of managers is also a typical example of an in-house career principle of managerial selection, which developed in Germany in the 1980s and continued into the 2000s (Windolf 2003; Hartmann 2018). Even those who gained international experience mostly did so in an office of their home company group abroad. The second most-dense network of managers from the automotive branch is their ties through policy organizational ties, e.g., think tanks and expert commissions, including those with the representatives of political elites (e.g., Atlantik-Brücke). ${ }^{9}$

In contrast to CEOs from the automotive branch, virtually all of CEOs in the chemistry branch worked abroad, as had more than half of CEOs from the logistics/ IT/finance branch. The recruitment patterns of this group of CEOs stems from the

\footnotetext{
${ }^{8}$ Current investigations of Dieselgate at the European level have shown, however, that German automotive groups (i.e., Volkswagen, Porsche, Audi, Daimler, and BMV) are less innovative as one may think and that they tried to overcome this low innovation through illegal collusion and cheating (European Commission 2019).

9 Interestingly, in 2018, German political parties received the highest amount of donations from the automotive sector of industry, followed by the construction and real estate sector (Sawatzki 2019).
} 
internationalization of the corporate environment in Germany, which has decreased the number of opportunities for in-house careers (Hartmann 1996, pp. 71-72; Freye 2010). Indeed, fewer than half of CEOs in each sector were drawn from the same corporate group - the lowest number across all examined sectors. In these branches, therefore, the external pool of candidates has been successfully established, which is an indicator of an open recruitment market (Höpner 2003). In addition to high internationalization, the chemistry and logistics/IT/finance branches are also highly professionalized. Executive experience seems to be a prerequisite for CEO candidates in these branches. CEOs from these branches have been particularly often engaged in the policy organizational networks.

The high degree of internationalization in these two branches explains the moderately dense networks within those branches. The strongest between-ties existed among CEOs of the chemical branch and the branches that either participate in the production process or are part of the supplier-consumer chain (e.g., the automotive CEOs). Connections of CEOs from the logistics/IT/finance sector with the others are particularly interesting. The moderate density of their networks across branches supports the thesis of the dissolution of Deutschland AG (Kengelbach and Roos 2006). However, what we need to consider is that managers from this branch still occupy an important brokerage position within the overall corporate network.

Similar to the CEOs from the automotive branch, CEOs from the trade branch have rarely gained any working experience abroad. The proportion of trade managers recruited from the same corporate group (i.e., those with in-house careers) fluctuated between 55 and $60 \%$, which is the second-lowest level among all branches. Finally, the proportion of these managers without any executive experience has been the highest among all examined branches (approximately 25\%). Because corporate careers in this branch do not necessarily require any specific educational and executive experience, managers in this sector have been, on average, younger than their counterparts in other sectors. These patterns of recruitment explain the low density of trade networks within their own branch and with other branches.

\section{Conclusion and implications}

This research is the first comparative empirical study focused on the small-world network among German CEOs by analyzing their affiliation ties (Watts 2004). The analysis of CEOs' affiliation networks revealed four main findings. First, the affiliation networks of German CEOs have all small-world features (i.e., a large local clustering coefficient and a short average path length). All the affiliation ties analyzed in this article are crucial to forming local neighborhoods with a high clustering coefficient, as is evident in many overlapping cliques within the overall network. The small-world network structure remained intact despite massive personnel changes in the management of top German companies between 2012 and 2015. This 
finding again supports one of the assumptions of the small-world theory (e.g., Watts and Strogatz 1998) that any additional random contact has a non-linear effect on the overall network connectivity. In other words, if few CEOs remain in their positions, doing so will create new short cuts among all the important CEOs and lead to the preservation of the small-world network features (Davis et al. 2003).

Second, regarding the average path length of the small-world network, German CEOs have only two degrees of separation from each other, even without any previous personal contacts. This finding implies that looking at interlocking directorates is not sufficient to identifying the dissolution of Germany AG (e.g., Höpner and Krempel 2006) because it ignores the existence of affiliation ties among the nation's top CEOs, which provide a short path length of the small-world network.

Third, supporting the assumptions drawn from the small-world theory (e.g., Newman et al. 2002), a large local clustering coefficient of the overall network suggests that CEOs tend to be connected through various ties. This study has revealed that if two German CEOs share charity or co-worker ties, there is a high probability that they are also connected through policy organizational ties.

Fourth, theoretical and empirical studies (e.g., Watts et al. 2002) have shown that small-world networks tend to be structured along two fundamental social dimensions: occupation and geography. The affiliation networks among Germany's top CEOs are no exception. They have been strongly connected through their industry-specific networks (the occupational dimension of the small-world networks) and their geographical networks (which measures the density of ties among German-born and non-German-born CEOs). This aspect of studies on German corporate elites has been a blind spot in the extant literature. Most importantly, this study showed that both dimensions do not operate separately but are interconnected. Using multiple correspondence analysis, this study reveals that the corporate elite in Germany consists of three distinct subgroups with specific recruitment and career patterns. These sub-groups also share distinct network characteristics. The first group consists of managers from the automotive and technical engineering branch who are highly educated in the technical and natural sciences, have in-house careers, and are usually German-born. These managers are exceptionally well connected within the overall affiliation network. The opposite holds true for managers from the trade branch, who often enter the corporate recruitment market as outsiders and have therefore been largely isolated within the network. The third group consists of managers from the chemistry and logistics/IT/finance branches who are internationally experienced (and often, foreigners), highly educated, and assume brokerage positions within the overall corporate network.

In addition to the ramifications for network analysis, this study has implications for general management and corporate governance perspectives. First, this study's findings contribute to the scholarly discussion of diversity at the CEO's level (Oakley 2000). The German CEOs' small-world has been virtually allmale, and each appointment of a female board member has been celebrated as a once-ina-lifetime event. For example, German pharmaceuticals giant Merck has shortly announced that as of May 2021, Belen Garijo (a Spanish-born manager) will be its new CEO, the first woman to lead a DAX 30-listed company. As of 2018, Germany's boards of directors of the 30 largest companies on the stock exchange 
had just $12 \%$ of female managers, compared to approximately $25 \%$ in the United States (AllBright Foundation 2018). Researchers have stressed the importance of daycare facilities, role models, mentorships, and organizational culture to increasing female representation in the top management positions (Oakley 2000; AllBright Foundation 2018). This study shows the importance of affiliation networks and their small-world character. Our findings imply that female candidates have to be strategically introduced to various affiliation networks (e.g., policy organizational networks), in addition to interlocking directorates, in order to become more visible candidates for CEO positions. Doing so will disrupt the 'old boys' connections that persist in the corporate world.

Second, this study has implications for the theory of corporate ethos or corporate character (Bucy 1991; Diamantis 2018), which examines the role of an organization's personality in its involvement in criminal acts. One of the most recent cases is 'Dieselgate', which involved Volkswagen and other renowned German automotive companies in a self-inflicted and extremely costly cheating scandal. Researchers have underlined the unethical way these companies managed this scandal (Mujkic and Klingner 2019; Markowitz et al. 2017). My study has shown that the CEOs of Germany's largest automotive companies have a similar background, career path, and mode of recruitment to their CEO position. As Bourdieu (1986) argues, similar background tends to produce a common way of thinking and common interests, i.e., habitus. In Dieselgate, CEOs for the automotive companies did work together to make cheating software and provide misleading information to the public authorities and consumers (Mujkic and Klingner 2019). It is perhaps too much to argue that the CEOs' shared background was the primary factor in their involvement in such criminal activities. Nevertheless, authorities, supervisory boards, and CEOs themselves have to be aware that a common background may serve as an additional source of trust and increase a CEO's willingness to participate in criminal activities.

Third, this study contributes to a general discussion about individual human capital and human capital resources within the context of CEO recruitment. Studies of CEO individual-level human capital have underlined the crucial importance of a new CEO's unique backgrounds, abilities, and skills to firm competitiveness (Lovelace et al. 2018). Upper echelons theory stresses that a top management team's composition and background that complement the CEO's background and skills determine whether strategic changes will be implemented and performance goals will be met (Nyberg et al. 2019). In Germany's case, establishing open recruitment markets and strategically recruiting top management teams and CEOs from different networks may decrease the importance of in-house careers for CEO appointments, positively affect firm performance and increase a CEO's chances of succeeding in this position.

The approach taken in this study opens up several avenues for further research on change in German corporate structures. First, future research must go beyond the existing studies on interlocking directorates and consider affiliation ties. These ties are important for CEOs; otherwise, they would not spend their time in various policy organizational meetings and gatherings for different charity organizations. Future studies have to examine more closely how affiliation ties between CEOs emerge and change over time. One of the possibilities would be a qualitative survey 
of CEOs about their affiliation ties, their strength, and the perceived importance of these connections to their careers.

Second, as this study shows, CEOs' affiliation networks and recruitment patterns are interlinked; the transformation of affiliation networks is a dynamic outcome of interrelations among different subgroups within the network, each with distinct educational, professional, and network characteristics. The question arises whether if CEOs from the automotive industry have been densely connected through affiliation ties with CEOs of the other industries, while CEOs from the trade industry have not, these sub-groups have also been differently connected through interlocking directorates. Future studies should reconsider the argument about the dissolution of corporate networks in the post-Deutschland AG period in a more nuanced way by considering the substitutive and compensatory mechanisms of affiliation ties that have emerged from the transformation of subgroups within the corporate network.

Our results have also revealed that within the overall corporate network, some groups of CEOs are better connected among each other than to the other CEOs (in the network theory terminology, cliques). Although each network has its cliques (e.g., Granovetter 1973; Borgatti et al. 2002), the first novel aspect of my research is the identification of the cross-industry character of these cliques. In Germany, managers from automotive and technical engineering often assumed important brokerage positions within the corporate network. Further research has to take into account the sub-structure of the corporate network and examine the effects of different types of networks on the company's performance and the CEO's behavior.

Acknowledgements The author thanks Dr. Michael Edinger for helpful comments and Alice Schlicker for research assistance.

Funding Open Access funding enabled and organized by Projekt DEAL.

\section{Compliance with ethical standards}

Conflict of interest No potential conflict of interest was reported by the author.

Open Access This article is licensed under a Creative Commons Attribution 4.0 International License, which permits use, sharing, adaptation, distribution and reproduction in any medium or format, as long as you give appropriate credit to the original author(s) and the source, provide a link to the Creative Commons licence, and indicate if changes were made. The images or other third party material in this article are included in the article's Creative Commons licence, unless indicated otherwise in a credit line to the material. If material is not included in the article's Creative Commons licence and your intended use is not permitted by statutory regulation or exceeds the permitted use, you will need to obtain permission directly from the copyright holder. To view a copy of this licence, visit http://creativecommons.org/licen ses/by/4.0/.

\section{References}

Albach, H., \& Kless, H.-P. (1982). Personelle Verflechtungen bei deutschen Industrieaktiengesellschaften. Zeitschrift für Betriebswirtschaft, 52, 959-977. 
Allbright Foundation. (2018). Germany Last Place. Corporations across the world get more women into top management. Available online: https://www.allbright-stiftung.de/berichte.

Barabasi, A.-L. (2002). Linked: A new science of networks. Cambridge, MA: Perseus.

Beyer, J. (2003). Deutschland AG aD: Deutsche Bank, Allianz und das Verflechtungszentrum des deutschen Kapitalismus. In W. Streeck \& M. Höpner (Eds.), Alle Macht dem Markt?: Fallstudien zur Abwicklung der Deutschland AG (pp. 118-146). Frankfurt am Main: Campus Verlag.

Beyer, J., \& Höpner, M. (2003). The disintegration of organised capitalism: German corporate governance in the 1990s. West European Politics, 26, 179-198.

Borgatti, S. P., Everett, M. G., \& Freeman, L. C. (2002). Ucinet 6 for Windows: Software for social network analysis. Harvard, MA: Analytic Technologies.

Bourdieu, P. (1986). The forms of capital. In J. Richardson (Ed.), Handbook of theory and research for the sociology of education (pp. 241-258). Westport, CT: Greenwood.

Bourdieu, P. (1996). The state nobility. Elite schools in the field of power. Cambridge, MA: Polity Press.

Bourdieu, P., \& de Saint Martin, M. D. (1978). Le patronat. Actes de la recherche en sciences sociales, 20, 3-82.

Brown, R., Gao, N., Lee, E., \& Stathopoulos, K. (2012). What are friends for? CEO networks, pay and corporate governance. In S. Boubaker, B. D. Nguyen, \& D. K. Nguyen (Eds.), Corporate governance: Recent developments and new trends (pp. 287-307). Berlin: Springer.

Bucy, P. H. (1991). Corporate ethos: Standard for imposing corporate criminal liability. Minnesota Law Review, 75(4), 1095-1184.

Bühlmann, F., David, T., \& Mach, A. (2012). The Swiss business elite (1980-2000): How the changing composition of the elite explains the decline of the Swiss company network. Economy and Society, 41, 199-226.

Bühlmann, F., Davoine, E., \& Ravasi, C. (2017). European top management careers: A field analytical approach. European Societies, 20, 453-477.

Burt, R. (1992). Structural holes: The social structure of competition. Harvard, MA: Harvard University Press.

Carroll, G. R., \& Teo, A. C. (1996). On the social networks of managers. Academy of Management Journal, 39, 421-440.

Chatman, J. A., \& Jehn, K. A. (1994). Assessing the relationship between industry characteristics and organizational culture: How different can you be? Academy of Management Journal, 37(3), 522-553.

Chidambaran, N. K., Kedia, S., \& Prabhala, N. (2011). CEO director connections and corporate fraud. Fordham University Schools of Business Research Paper.

Chikh, S., \& Filbien, J. Y. (2011). Acquisitions and CEO power: Evidence from French networks. Journal of Corporate Finance, 17(5), 1221-1236.

Davis, G. F., Yoo, M., \& Baker, W. E. (2003). The small world of the American corporate elite, 19822001. Strategic Organization, 1(3), 301-326.

Davoine, E., \& Ravasi, C. (2013). The relative stability of national career patterns in European top management careers in the age of globalization. A comparative study in France/Germany/Great Britain and Switzerland. European Management Journal, 31, 152-163.

De Nooy, W. (2003). Fields and networks: Correspondence analysis and social network analysis in the framework of field theory. Poetics, 31, 305-327.

Diamantis, M. E. (2018). Clockwork corporations: Character theory of corporate punishment. Iowa Law Review, 103(2), 507-570.

Dodds, P. S., Muhamad, R., \& Watts, D. J. (2003). An experimental study of search in global social networks. Science, 301(5634), 827-829.

Egan, M. (1997). Modes of business governance: European management styles and corporate cultures. West European Politics, 20, 1-21.

Engelberg, J., Gao, P., \& Parsons, C. A. (2013). The price of a CEO's Rolodex. The Review of Financial Studies, 26(1), 79-114.

Entorf, H., Gattung, F., Möbert, J., \& Pahlke, I. (2009). Aufsichtsratsverflechtungen und ihr Einfluss. Zeitschrift für Betriebswirtschaft, 79, 1113-1141.

European Commission. (2019). Antitrust: Commission sends Statement of Objections to BMW, Daimler and VW for restricting competition on emission cleaning technology (April 5, 2019). http://europ a.eu/rapid/press-release_IP-19-2008_en.htm. Accessed on June 29, 2019.

Fennema, M., \& Schijf, H. (1978). Analysing interlocking directorates: Theory and methods. Social Networks, 1, 297-332. 
Fifka, M. S. (2013). Corporate citizenship in Germany and the United States-Differing perceptions and practices in transatlantic comparison. Business Ethics: A European Review, 22, 341-356.

Freye, S. (2010). Germany's new top managers? The corporate elite in flux, 1960-2005. Max-PlanckInstitute for the Study of Societies discussion Paper 10/10. http://edoc.vifapol.de/opus/vollt exte/2011/3017/pdf/dp10_10.pdf. Accessed on June 29, 2019.

Gergs, H., \& Schmidt, R. (2002). Generationswechsel im Management ost-und westdeutscher Unternehmen. Kölner Zeitschrift für Soziologie und Sozialpsychologie, 54, 553-578.

Granovetter, M. S. (1973). The strength of weak ties. American Journal of Sociology, 78(6), 1360-1380.

Granovetter, M. (2005). The impact of social structure on economic outcomes. Journal of Economic Perspectives, 19(1), 33-50.

Hall, P., \& Soskice, D. (Eds.). (2001). Varieties of capitalism: The institutional foundations of comparative advantage. Oxford: Oxford University Press.

Hartmann, H. (1956). Der zahlenmäßige Beitrag der deutschen Hochschulen zur Gruppe der industriellen Führungskräfte. Zeitschrift für die gesamte Staatswissenschaft, 1, 144-163.

Hartmann, M. (1996). Topmanager: Die Rekrutierung einer Elite. Frankfurt am Main: Campus Verlag.

Hartmann, M. (2018). Economic elites. In H. Best, J. Higley, M. Cotta, J.-P. Daloz, U. Hoffmann-Lange, J. Pakulski, \& E. Semenova (Eds.), The Palgrave handbook of political elites (pp. 399-416). London: Palgrave Macmillan.

Heemskerk, E. M. (2007). Decline of the corporate community: Network dynamics of the Dutch business elite. Amsterdam: Amsterdam University Press.

Heinze, Th. (2004). Dynamics in the German system of corporate governance? Empirical findings regarding interlocking directorates. Economy and Society, 33, 218-238.

Höpner, M. (2003). Wer beherrscht die Unternehmen? Shareholder Value, Managerherrschaft und Mitbestimmung in Deutschland. Frankfurt am Main: Campus Verlag.

Höpner, M., \& Krempel, L. (2006). Ein Netzwerk in Auflösung: Wie die Deutschland AG zerfällt, MaxPlanck-Institute for the Study of Societies. http://pubman.mpdl.mpg.de/pubman/item/escidoc:19139 19/component/escidoc:1913917/Netzwerk_in_Aufloesung-w.pdf. Accessed on June 29, 2019.

Hwang, B. H., \& Kim, S. (2009). It pays to have friends. Journal of Financial Economics, 93(1), $138-158$.

IJCS. (2012). Special Issue on Interlocking corporate directorates in comparative perspective. International Journal of Comparative Sociology, 54, 247-342.

Keller, F. B. (2018). Analyses of elite networks. In H. Best, J. Higley, M. Cotta, J.-P. Daloz, U. HoffmannLange, J. Pakulski, \& E. Semenova (Eds.), The Palgrave handbook of political elites (pp. 135-152). London: Palgrave Macmillan.

Kengelbach, J., \& Roos, A. (2006). Entflechtung der Deutschland AG. The Boston Consulting Group GmbH, Sonderdruck aus M\&A Review, 1, 12-21.

Kenis, P., \& Schneider, V. (1991). Policy networks and policy analysis: Scrutinizing a new analytical toolbox. In B. Marin \& R. Mayntz (Eds.), Policy networks: Empirical evidence and theoretical considerations (pp. 25-59). Frankfurt a. M.: Campus Verlag.

Kirchmaier, T., \& Stathopoulos, K. (2008). From fiction to fact: The impact of CEO social networks (No. 537). Manchester Business School Working Paper.

Klein, H., \& Höntzsch, T. (2007). Fliegende Wechsel-die Drehtür kreist. Zwei Jahre danach-was macht die Ex-Regierung Schröder II heute. Available online: www.lobbycontrol.de.

Kleinberg, J. (2000). Navigation in a small world. Nature, 406, 845.

Knoke, D. (2018). Power networks. In H. Best, J. Higley, M. Cotta, J.-P. Daloz, U. Hoffmann-Lange, J. Pakulski, \& E. Semenova (Eds.), The Palgrave handbook of political elites (pp. 539-561). London: Palgrave Macmillan.

Knoke, D., \& Yang, S. (2020). Social network analysis. Thousand Oaks, California: Sage Publications.

Krackhardt, D. (1987). Cognitive social structures. Social Networks, 9, 109-134.

Larson, A. (1992). Network dyads in entrepreneurial settings: A study of the governance of exchange relationships. Administrative Science Quarterly, 37, 76-104.

LeRoux, B., \& Rouanet, H. (2010). Multiple correspondence analysis. Los Angeles: Sage Publications.

Lovelace, J. B., Bundy, J., Hambrick, D. C., \& Pollock, T. G. (2018). The shackles of CEO celebrity: Sociocognitive and behavioral role constraints on "star" leaders. Academy of Management Review, 43(3), 419-444.

Maclean, M., Harvey, C., \& Kling, G. (2014). Pathways to power: Class, hyper-agency and the French corporate elite. Organization Studies, 35, 825-855. 
Mariotti, F., \& Delbridge, R. (2012). Overcoming network overload and redundancy in interorganizational networks: The roles of potential and latent ties. Organization Science, 23(2), 511-528.

Markowitz, E. M., Chapman, D. A., Guckian, M. L., \& Lickel, B. (2017). A corporate scandal that hits close to home: Examining owners' responses to the Volkswagen diesel emissions scandal. Environmental Communication, 11(6), 740-755.

McDonald, M. L., \& Westphal, J. D. (2003). Getting by with the advice of their friends: CEOs' advice networks and firms' strategic responses to poor performance. Administrative Science Quarterly, 48(1), 1-32.

Milgram, S. (1967). The small world problem. Psychology Today, 2(1), 60-67.

Mills, C. W. (1956). The power elite. New York: Oxford University Press.

Mujkic, E., \& Klingner, D. (2019). Dieselgate: How hubris and bad leadership caused the biggest scandal in automotive history. Public Integrity, 19, 365-377.

Nahapiet, J., \& Ghoshal, S. (1998). Social capital, intellectual capital, and the organizational advantage. Academy of Management Review, 23(2), 242-266.

Newman, M. E., Watts, D. J., \& Strogatz, S. H. (2002). Random graph models of social networks. Proceedings of the National Academy of Sciences, 99(suppl 1), 2566-2572.

Nyberg, A. J., Ployhart, R. E., \& Moliterno, T. P. (2019). Human capital resources: A convergence of questions but divergence of answers. In A. J. Nyberg \& T. P. Moliterno (Eds.), Handbook of research on strategic human capital resources (pp. 502-512). Cheltenham, UK; Northampton, MA: Edward Elgar Publishing.

Oakley, J. G. (2000). Gender-based barriers to senior management positions: Understanding the scarcity of female CEOs. Journal of Business Ethics, 27(4), 321-334.

Pappi, F. U., Kappelhoff, P., \& Melbeck, Ch. (1987). Die Struktur der Unternehmensverflechtungen in der Bundesrepublik. Kölner Zeitschrift für Soziologie und Sozialpsychologie, 39, 693-717.

Plian, P. H. (1995). Human capital or social networks: What constrains CEO dismissals? Academy of Management Proceedings, 1995(1), 37-41.

PricewaterhouseCoopers. (2018). CEO Success Study. Analyse der CEO-Wechsel im deutschsprachigen Raum \& global. September 2018. Strategy \& Briefing document. https://www.strategyand.pwc.com/ media/file/CEO-Success-Study2018_DE.pdf. Accessed on June 29, 2019.

Rhodes, R. A. W. (1990). Policy networks: A British perspective. Journal of Theoretical Politics, 2, 293-317.

Saiia, D., Carroll, A., \& Buchholtz, A. (2003). Philanthropy as strategy: When corporate charity "begins at home." Business \& Society, 42, 169-201.

Sawatzki, A. (2019). Parteispenden 2018: Immobilienlobby legt zu. https://www.lobbycontr ol.de/2019/01/parteispenden-2018-immobilienlobby-legt-zu/. Accessed on June 29, 2019.

Schörner, M. (2017). Public Affairs, Government Relations und Lobbying: Die Interessenvertretung deutscher Großunternehmen gegenüber der Politik und Verwaltung in Deutschland. Münster: LIT Verlag.

Scott, J. (1991). Networks of corporate power: A comparative assessment. Annual Review of Sociology, 17, 181-203.

Stephenson, S. (2015). Gangs of Russia: From the streets to the corridors of power. Ithaca, NY: Cornell University Press.

Stokman, F. N., Ziegler, R., \& Scott, J. (1985). Networks of corporate power: A comparative analysis of ten countries. Cambridge: Polity Press.

Streeck, W. (1997). German capitalism: Does it exist? Can it survive? New Political Economy, 2, 237-256.

Travers, J., \& Milgram, S. (1977). An experimental study of the small world problem. In S. Leinhardt (Ed.), Social networks: A developing paradigm (pp. 179-197). New York: Academic Press.

Tsui, A. S., Zhang, Z. X., Wang, H., Xin, K. R., \& Wu, J. B. (2006). Unpacking the relationship between CEO leadership behavior and organizational culture. The Leadership Quarterly, 17(2), 113-137.

Uzzi, B. (1997). Social structure and competition in interfirm networks: The paradox of embeddedness. Administrative Science Quarterly, 42(1), 35-67.

Watts, D. J. (2004). The "new" science of networks. Annual Review of Sociology, 30, 243-270.

Watts, D. J., \& Strogatz, S. H. (1998). Collective dynamics of 'small-world' networks. Nature, 393(6684), $440-442$.

Watts, D. J., Dodds, P. S., \& Newman, M. E. (2002). Identity and search in social networks. Science, 296(5571), 1302-1305. 
Windolf, P. (2003). Sind Manager Unternehmer? Deutsche und britische Manager im Vergleich. In S. Hradil \& P. Imbusch (Eds.), Oberschichten-Eliten-Herrschende Klassen (pp. 299-336). Opladen: Leske + Budrich.

Windolf, P., \& Nollert, M. (2001). Institutionen, Interessen, Netzwerke. Unternehmensverflechtung im internationalen Vergleich. Politische Vierteljahresschrift, 42, 51-78.

Zhang, Y., \& Rajagopalan, N. (2003). Explaining new CEO origin: Firm versus industry antecedents. Academy of Management Journal, 46(3), 327-338.

Ziegler, R. (1981). Eine netzwerkanalytische Untersuchung der Personalverflechtungen großer Wirtschaftsunternehmen. In W. Schulte (Ed.), Soziologie in der Gesellschaft (pp. 706-710). Bremen. http://nbn-resolving.de/urn:nbn:de:0168-ssoar-189454.

Publisher's Note Springer Nature remains neutral with regard to jurisdictional claims in published maps and institutional affiliations.

Elena Semenova is assistant professor at the Free University of Berlin. Her most recent book is The Palgrave Handbook of Political Elites (2018, co-edited with H. Best, J. Higley, M. Cotta, J.-P. Daloz, U. Hoffmann-Lange and J. Pakulski). 